\title{
Penerapan Teknologi Sel Surya Pada Penerangan Jalan Umum Di Dusun Gitaq Demung Desa Genggelang Kecamatan Gangga Kabupaten Lombok Utara
}

\author{
A. Sjamsjiar Rachman, Muhamad Syamsu Iqbal, Misbahuddin, \\ Syafaruddin, Giri Wahyu Wiriasto
}

Program Studi Teknik Elektro Universitas Mataram

Alamat korespondensi : asrachman@unram.ac.id

\begin{abstract}
ABSTRAK
Gempa darat berkekuatan 6.5 Mw yang melanda Lombok Timur NTB tanggal 19 Agustus 2018. Peristiwa tersebut adalah gempa bumi ketiga yang menerjang Lombok setelah Gempa bumi Lombok Juli 2018 dan Gempa bumi Lombok 5 Agustus 2018. Lombok Utara adalah daerah yang paling terdampak gempa karena berdekatan dengan pusat gempa $7 \mathrm{Mw}$. Sejumlah wilayah yang potensial dan infrasruktur Penerangan Jalan Umum (PJU) Kabupaten Lombok Utara rusak parah, khususnya di Dusun Gitaq Demung, Desa Genggelang, Kecamatan Gangga. Karena persoalan keterbatasan penerangan jalan umum, maka dalam kegiatan pengabdian masyarakat ini, tim membantu merevitalisasi PJU di daerah sekitar Dusun Gitaq Demung, serta kaitannya dengan tersedianya sumber energi listrik bagi warga. Sebagai tahapan lanjutan dalam mengatasi berbagai hambatan infrastruktur vital lainnya, dan menyiapkan infrastruktur pendukung, maka tim memberikan bantuan dalam bentuk kegiatan pelatihan perancangan dan pemasangan PJU dengan memanfaatkan sel surya sebagai cadangan energi secara terbatas.
\end{abstract}

Kata kunci: Bencana, Gempa, Infrastruktur, PJU, Sel Surya

\section{PENDAHULUAN}

Suatu penerangan diperlukan oleh manusia untuk mengenali suatu obyek secara visual. Penerangan jalan umum dibuat untuk mempermudah dan membantu manusia dalam melihat obyek di jalan pada waktu malam hari atau suasana gelap. Suatu daerah tanpa lampu penerangan jalan akan seperti daerah mati, dan kemungkinan akan terjadi banyak kasus kejahatan, kecelakaan lalulintas, dan akan berdampak buruk pada kehidupan sosial pada malam hari. Suatu daerah dengan penerangan lampu jalan yang baik, akan menjadikan wajah daerah menjadi lebih baik dan indah. Selain itu berdampak lebih baik terhadap kehidupan sosial masyarakat. Salah satu pembangunan infrastruktur daerah adalah pembangunan dan pemasangan lampu penerangan jalan umum. Dalam pelaksanaan pembangunan lampu penerangan jalan umum diperlukan perencanaan yang baik, sehingga pemasangan lampu penerangan jalan umum tersebut mempunyai efisiensi yang tinggi, mempunyai kuat penerangan yang cukup dan biaya operasional yang murah.

Salah satu cara memperoleh tujuan tersebut adalah dengan memilih jenis lampu yang tepat, yang akan digunakan sebagai lampu penerangan jalan umum. Dan intensitas lampu 
penerangan jalan umum harus sesuai dengan ketentuan agar lampu penerangan jalan umum dapat beroprasi dengan baik.

Rusaknya infrastruktur PJU di Dusun Gitaq Demung, maka di lingkungan dusun tersebut jika malam hari sangat gelap. Hal ini sangat menyulitkan aktivitas warga dengan lingkungan sekitarnya menjadi terbatas. Oleh karena itu kegitan pengabdian pada masyatakat ini mengangkat tema "Revitalisasi Terbatas PJU yang difokuskan pada Dusun Gitaq Demung, Desa Genggelang, Kecamatan Gangga, Kabupaten Lombok Utara".

Berdasarkan latar belakang yang telah di uraikan di atas dapat dirumuskan masalahnya adalah sebagai berikut:

1. Bagaimana cara mengevaluasi penerangan lampu jalan

2. Bagaimana spesifikasi penerangan lampu jalan

3. Bagaimana kesesuaian dengan ketentuan yang berlaku tentang intensitas penerangan lampu jalan umum (PJU) di Dusun Gitaq Demung, Desa Genggelang, Kecamatan Gangga, Kabupaten Lombok Utara.

Tujuan dan manfaat pengabdian masyarakat ini adalah:

1. Merevitalisasi PJU dalam bentuk memberikan bantuan pembangunan kembali PJU yang rusak akibat gempa.

2 .Untuk mengetahui cara mengevaluasi spesifikasi dan penerangan lampu jalan yang dibutuhkan.

3. Untuk mengetahui kesesuaian ketentuan yang berlaku tentang intensitas penerangan jalan.

4. Melakukan perencanaan dan pemasangan yang dapat menghasilkan fungsi PJU yang efisien, sehingga dapat memberikan kenyamanan pada malam hari, meningkatkan keselamatan, keamanan lingkungan, serta keindahan lingkungan.

\section{METODE KEGIATAN}

Kegiatan pengabdian kepada masyarakat ini dilaksanakan dalam beberapa tahapan dan menggunakan beberapa metode, yaitu:

1) Observasi: pengamatan dilakukan langsung ke lokasi untuk mengetahui kondisi lingkungan, kontur dan topologi lingkungan Dusun Gitaq Demung, Desa Genggelang, Kecamatan Gangga, Kabupaten Lombok Utara.

2) Ceramah dan diskusi: menyampaikan pengenalan perencanaan PJU yang sesuai Badan Standardisasi Nasional dan American Standard Practice For Roadway Lightning of Illuminating Enginering Society yang disesuaikan dengan kondisi yang ada di Dusun Gitaq Demung, Desa Genggelang, Kecamatan Gangga, Kabupaten Lombok Utara.

3) Praktik dan pendampingan: dimaksudkan untuk lebih mendalami materi penyuluhan yang telah diberikan. Proses pendampingan dilakukan di lokasi dan dilanjutkan dengan pendampingan melalui kegiatan revitalisasi atau pembangunan kembali PJU.

4) Evaluasi dan penyusunan laporan: termasuk di dalamnya melakukan evaluasi atas kesiapan fasilitas pendukung untuk menerapkan perencanaan PJU sesuai kondisi lingkungan ada dan 
dana yang ada (terbatas), serta sarana pendukung lainnya. Setelah itu, dilakukan penyusunan laporan pengabdian masyarakat

\section{HASIL DAN PEMBAHASAN}

Diagram alir kegiatan Revitalisasi Penerangan Jalan Umum di Dusun Gitaq Demung, Desa Genggelang, Kecamatan Gangga, Kabupaten Lombok Utara, diperlihatkan pada Gambar 1. Berdasarkan observasi yang dilakukan, maka diperoleh data sekunder, data primer dan data perhitungan mengenai kondisi penerangan jalan umum di Dusun Gitaq Demung.

Kegiatan pengabdian masyarakat dimulai dengan melakukan beberapa kali observasi dan pengamatan langsung ke lokasi untuk mengetahui kondisi lingkungan, geografis, kontur dan topologi di Dusun Gitaq Demung, Desa Genggelang, Kecamatan Gangga, Kabupaten Lombok Utara.

Dari hasil observasi, pengukuran, perhitungan dan diskusi tentang gambaran umum lokasi, lebar dan panjang jalan, jenis dan tinggi tiang, jenis lampu yang terpasang, dan tingkat iluminasi, dihasilkan data perancangan iluminasi dengan 2 (dua) model susunan lampu SingleSide dan Staggered dan 2 (dua) jenis lampu, SON-T 150W dan HPL-N 250W. (lihat Gambar 2 dan Gambar 3).

Perancangan model susunan lampu Single Side (Satu Sisi) dengan 2 (dua) jenis lampu, SON-T 150W dan HPL-N 250W

Dari hasil perancangan sistem penataan lampu jalan dengan model susunan Single Side (Satu Sisi) dengan 2 (dua) jenis lampu, SON-T 150W dan HPL-N 250W seperti diperlihatkan Gambar 7 dan Tabel Data Perancangan Iluminasi seperti diperlihatkan Tabel 1 dan Tabel 2.

Perancangan model susunan lampu Staggered (Selang-seling) dengan 2 (dua) jenis lampu, SON-T 150W dan HPL-N 250W

Dari hasil perancangan sistem penataan lampu jalan dengan model susunan Staggered (Selang-Seling) dengan 2 (dua) jenis lampu, SON-T 150W dan HPL-N 250W seperti diperlihatkan Gambar 8 dan Tabel Data Perancangan Iluminasi seperti diperlihatkan Tabel 3 dan Tabel 4. 


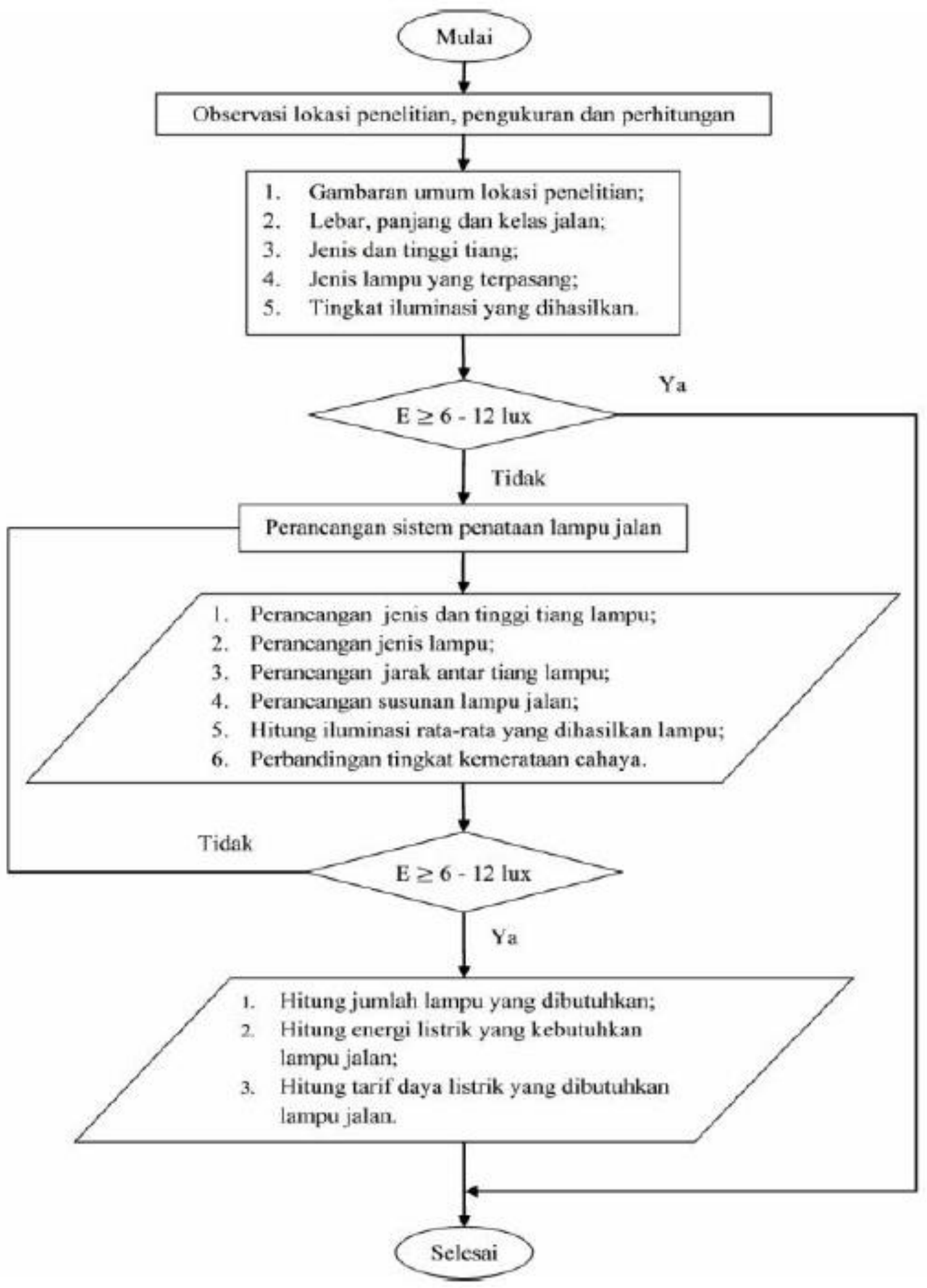

Gambar 1 Diagram Alir Kegiatan Pengabdian pada Masyarakat 
Sedangkan dari data perancangan penataan lampu penerangan jalan yang telah dilakukan dengan kondisi lebar jalan yang sama, yaitu 6 meter dan menggunakan jenis dan tinggi tiang lampu yang sama yaitu 10 meter serta panjang lengan lampu 2 meter, maka sebagai perbandingan perancangan penggunaan lampu yang akan digunakan dengan total panjang jalan $250 \mathrm{~m}$ adalah lampu sodium bertekanan tinggi (HPS) jenis SON-T 150 Watt dan lampu mercury bertekanan tinggi (HPM) jenis HPL-N 250 Watt seperti terlihat pada Tabel 4.

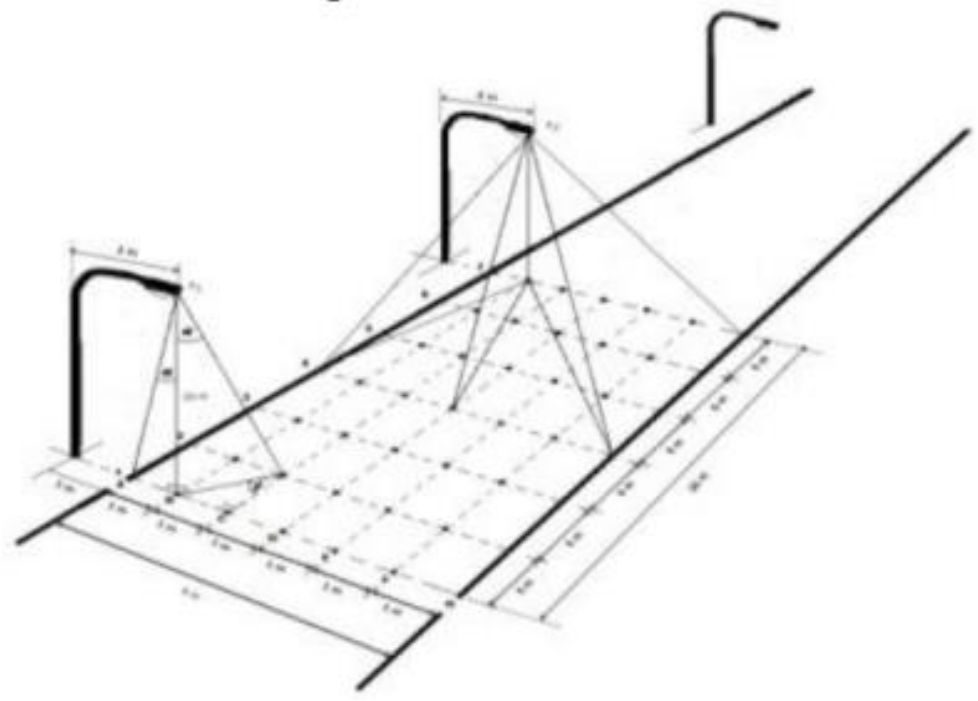

Gambar 2 Perancangan Lampu Jalan Model Single Side (Satu Sisi)

Tabel 1 Perancangan Iluminasi Model Single Side menggunakan Jenis Lampu SON-T 150W

\begin{tabular}{|c|c|c|c|c|c|c|c|c|}
\hline \multirow{2}{*}{\multicolumn{2}{|c|}{$\begin{array}{c}\text { Titik } \\
\text { Pencahayaan } \\
\text { (lux) }\end{array}$}} & \multicolumn{7}{|c|}{$\begin{array}{l}\text { Jarak Antar Tiang Lampu } \\
\qquad 31 \mathrm{~m}\end{array}$} \\
\hline & & 1 & 2 & 3 & 4 & 5 & 6 & 7 \\
\hline \multirow{7}{*}{ 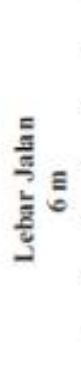 } & A & 11,99 & 7,83 & 3,79 & 2,72 & 3,79 & 7,83 & 11,99 \\
\hline & B & 12,17 & 7,91 & 3,81 & 2,74 & 3,81 & 7,91 & 12,17 \\
\hline & C & 11,99 & 7,83 & 3,79 & 2,72 & 3,79 & 7,83 & 11,99 \\
\hline & D & 11,51 & 7,58 & 3.73 & 2,70 & 3,73 & 7,58 & 11,51 \\
\hline & E & 10,72 & 7,21 & 3,62 & 2,64 & 3,62 & 7,21 & 10,72 \\
\hline & F & 9,78 & 6,74 & 3,52 & 2,58 & 3,52 & 6,74 & 9,78 \\
\hline & G & 8,76 & 6,20 & 3,35 & 2,50 & 3,35 & 6,20 & 8,76 \\
\hline
\end{tabular}

Keterangan :

- Jarak antara setiap titik pencahayaan dari titik 1 sampai titik $7=5,16$ meter

- Jarak antara setiap titik pencahayaan dari titik A sampai titik $\mathrm{G}=1$ meter

- Iluminasi rata-rata $=6,66 \mathrm{Lux}$

- Perbandingan tingkat kemerataan cahaya $=2,66: 1$ 
Tabel 2 Perancangan Iluminasi Model Single Side menggunakan Jenis Lampu HPL-N 250W

\begin{tabular}{|c|c|c|c|c|c|c|c|c|}
\hline \multirow{2}{*}{\multicolumn{2}{|c|}{$\begin{array}{c}\text { Titik } \\
\text { Pencahayaan } \\
\text { (lux) }\end{array}$}} & \multicolumn{7}{|c|}{$\begin{array}{c}\text { Jarak Antar Tiang Lampu } \\
31 \mathrm{~m}\end{array}$} \\
\hline & & 1 & 2 & 3 & 4 & 5 & 6 & 7 \\
\hline \multirow{7}{*}{ 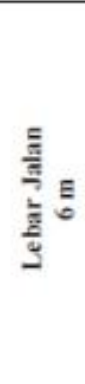 } & $A$ & 10,25 & 7,49 & 4,22 & 3,22 & 4,22 & 7,49 & 10,25 \\
\hline & B & 10,40 & 7,58 & 4,24 & 3,24 & 4,24 & 7,58 & 10,40 \\
\hline & $\mathrm{C}$ & 10,25 & 7,49 & 4,22 & 3,22 & 4,22 & 7,49 & 10,25 \\
\hline & D & 9,82 & 7,24 & 4,14 & 3,18 & 4,14 & 7,24 & 9,82 \\
\hline & E & 9,18 & 6,87 & 4,01 & 3,10 & 4,01 & 6,87 & 9,18 \\
\hline & $F$ & 8,38 & 6,39 & 3,85 & 3,02 & 3,85 & 6.39 & 8,38 \\
\hline & G & 7,51 & 5,86 & 3,65 & 2,90 & 3,65 & 5,86 & 7,51 \\
\hline
\end{tabular}

Keterangan :

- Jarak antara setiap titik pencahayaan dari titik 1 sampai titik $7=5,16$ meter

- Jarak antara setiap titik pencahayaan dari titik A sampai titik $\mathrm{G}=1$ meter

- Iluminasi rata-rata $=6,28 \mathrm{Lux}$

- Perbandingan tingkat kemerataan cahaya $=2,17: 1$

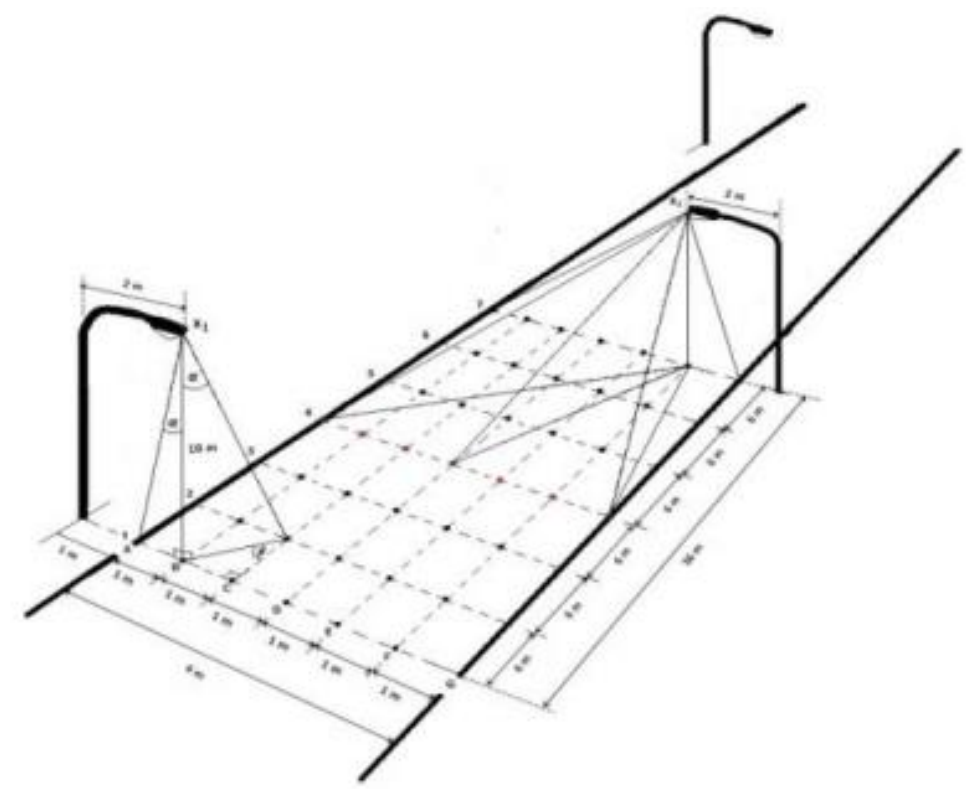

Gambar 3 Perancangan Lampu Jalan Model Staggered (Selang-seling)

Dari perancangan yang dilakukan di atas, maka diambil pilihan yang efisien dan ekonomis adalah dengan menggunakan jenis lampu SON-T 150 watt dengan jumlah 7 (tujuh) titik lampu.

Kegiatan pengabdian dilanjutkan seperti diperlihatkan pada Gambar 4, dengan melakukan diskusi-diskusi kecil dengan berbagai pihak, mulai dari Kepala Dusun Gitaq Demung, masyarakat sekitar dan beberapa orang yang berkepentingan dalam revitalisasi PJU. 
Materi tentang perencanaan dan aspek-aspek teknologi PJU, diberikan dengan metode ceramah dan dilanjutkan dengan diskusi.

Tabel 3 Perancangan Iluminasi Model Single Side menggunakan Jenis Lampu SON-T 150W

\begin{tabular}{|c|c|c|c|c|c|c|c|c|}
\hline \multirow{2}{*}{\multicolumn{2}{|c|}{$\begin{array}{c}\text { Titik } \\
\text { Pencahayaan } \\
\quad \text { (lux) }\end{array}$}} & \multicolumn{7}{|c|}{$\begin{array}{c}\text { Jarak Antar Tiang Lampu } \\
\qquad 36 \mathrm{~m}\end{array}$} \\
\hline & & 1 & 2 & 3 & 4 & 5 & 6 & 7 \\
\hline \multirow{7}{*}{ 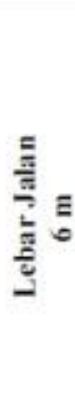 } & $\mathbf{A}$ & 11,99 & 7,83 & 3,79 & 2,72 & 3,79 & 7,83 & 11,99 \\
\hline & B & 12,17 & 7,91 & 3,81 & 2,74 & 3.81 & 7,91 & 12.17 \\
\hline & C & 11,99 & 7,83 & 3,79 & 2,72 & 3,79 & 7,83 & 11,99 \\
\hline & D & 11,51 & 7,58 & 3,73 & 2,70 & 3,73 & 7.58 & 11,51 \\
\hline & $\mathbf{E}$ & 10,72 & 7,21 & 3,62 & 2.64 & 3,62 & 7,21 & 10,72 \\
\hline & $\mathbf{F}$ & 9,78 & 6,74 & 3,52 & 2,58 & 3,52 & 6,74 & 9,78 \\
\hline & G & 8.76 & 6.20 & 3.35 & 2.50 & 3,35 & 6.20 & 8.76 \\
\hline
\end{tabular}

Keterangan :

- Jarak antara setiap titik pencahayaan dari titik 1 sampai titik $7=6$ meter

- Jarak antara setiap titik pencahayaan dari titik A sampai titik $\mathrm{G}=1$ meter

- Iluminasi rata-rata $=6,66 \mathrm{Lux}$

- Perbandingan tingkat kemerataan cahaya $=2,54: 1$

Tabel 4 Perancangan Iluminasi Model Single Side menggunakan Jenis Lampu HPL-N 250W

\begin{tabular}{|c|c|c|c|c|c|c|c|c|}
\hline \multirow{2}{*}{\multicolumn{2}{|c|}{$\begin{array}{c}\text { Titik } \\
\text { Pencahayaan } \\
\quad \text { (lux) }\end{array}$}} & \multicolumn{7}{|c|}{$\begin{array}{c}\text { Jarak Antar Tiang Lampu } \\
\qquad 36 \mathrm{~m}\end{array}$} \\
\hline & & 1 & 2 & 3 & 4 & 5 & 6 & 7 \\
\hline \multirow{7}{*}{$\begin{array}{l}\frac{5}{\sqrt[n]{5}} \\
\frac{5}{5} \\
\frac{5}{5} \\
\frac{5}{5}\end{array}$} & A & 10.25 & 7,49 & 4,22 & 3.22 & 4.22 & 7,49 & 10,25 \\
\hline & B & 10,40 & 7,58 & 4,24 & 3,24 & 4.24 & 7,58 & 10,40 \\
\hline & C & 10.25 & 7,49 & 4,22 & 3,22 & 4.22 & 7,49 & 10,25 \\
\hline & D & 9,82 & 7,24 & 4,14 & 3,18 & 4,14 & 7,24 & 9,82 \\
\hline & $\mathbf{E}$ & 9,18 & 6,87 & 4,01 & 3,10 & 4,01 & 6,87 & 9,18 \\
\hline & $\mathbf{F}$ & 8,38 & 6.39 & 3,85 & 3,02 & 3,85 & 6.39 & 8.38 \\
\hline & G & 7,51 & 5,86 & 3,65 & 2,90 & 3,65 & 5,86 & 7,51 \\
\hline
\end{tabular}

Keterangan :

- Jarak antara setiap titik pencahayaan dari titik 1 sampai titik $7=6$ meter

- Jarak antara setiap titik pencahayaan dari titik A sampai titik $\mathrm{G}=1$ meter

- Iluminasi rata-rata $=6,31 \mathrm{Lux}$

- Perbandingan tingkat kemerataan cahaya $=2,06: 1$ 
Setelah melakukan diseminasi teknologi penerangan jalan umum (PJU), serta diskusi yang lebih mendalam, selanjutnya diberikan pendampingan teknis dan memperkenalkan perangkat teknologi PJU berbasis energi terbarukan seperti sel surya dan angin. Proses pendampingan yang dilakukan di lokasi dilanjutkan dengan pendampingan teknis jarak jauh melalui sarana komunikasi yang ada.

Sebagai rangkaian akhir dari kegiatan pada skema kegiatan pengabdian tahun ini, dilakukan kunjungan-kunjungan untuk melakukan evaluasi persiapan fasilitas pendukung untuk menerapkan teknologi PJU yang lebih ekonomis dan efisien. Selanjutnya, kegiatan dipungkasi dengan diskusi-diskusi dalan tim untuk melengkapi evaluasi dan penyusunan laporan pengabdian masyarakat.

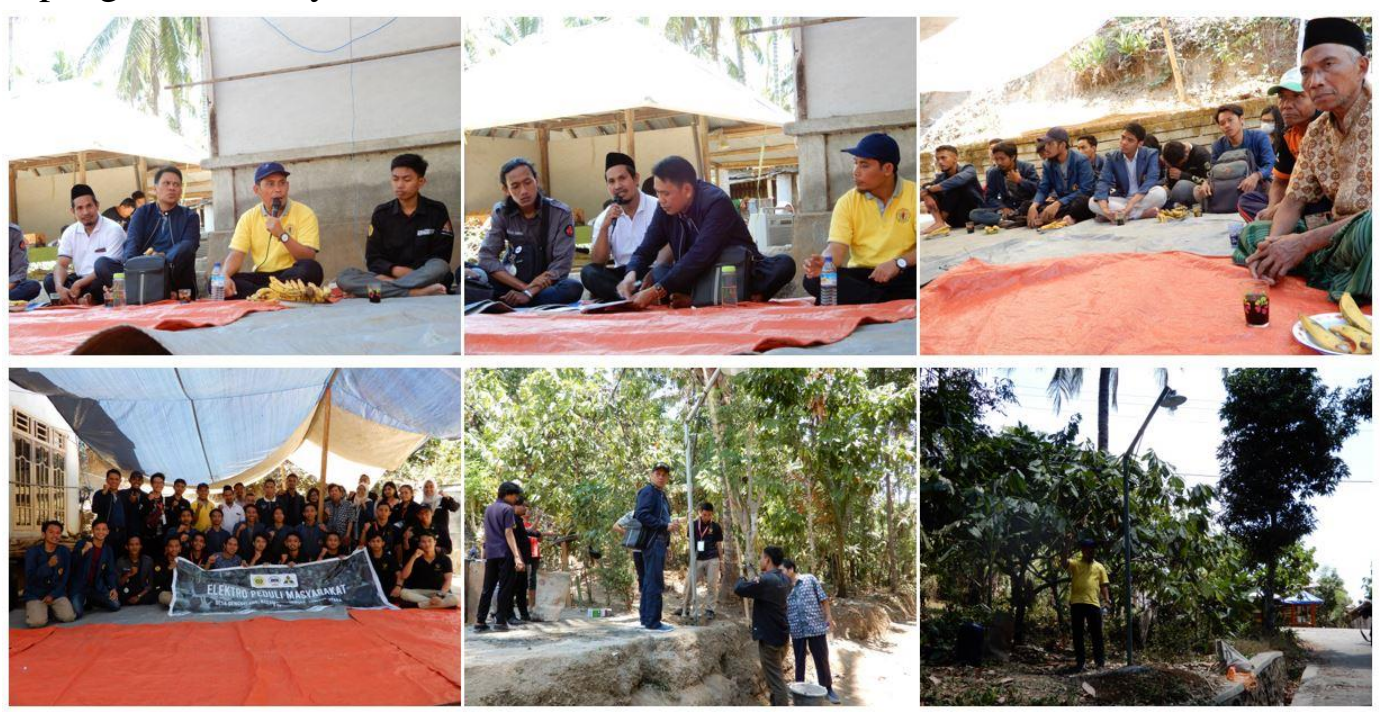

Gambar 4 Foto Kegiatan Pengabdian

\section{KESIMPULAN DAN SARAN}

Setelah dilakukan analisa data lampu penerangan jalan umum di Dusun Gitaq Demung dan analisa data perancangan, dapat disimpulkan bahwa:

1. Sistem penataan lampu penerangan jalan umum di Dusun Gitaq Demung yang terpasang saat ini masih belum memenuhi standar penerangan jalan yang berlaku, yaitu $6-12$ lux. Berdasarkan data pengukuran iluminasi rata-rata yang dihasilkan adalah 1,30 lux. Sedangkan berdasarkan hasil perhitungan iluminasi rata-rata yang dihasilkan adalah 1,44 lux. Hal ini disebabkan karena jenis lampu yang digunakan tidak efisien dengan kondisi jalan di Dusun Gitaq Demung yaitu menggunakan lampu HPL-N 80 Watt dan jarak tiang lampu yang terpasang terlalu jauh dari perkerasan jalan aspal yaitu 4 - 6 meter, serta jarak antar tiang lampu yang terpasang juga terlalu jauh yaitu 100 - 150 meter. Sehingga hal ini dapat mempengaruhi kuat cahaya/iluminasi yang dihasilkan pada permukaan jalan.

2. Sistem penataan lampu penerangan jalan umum di Dusun Gitaq Demung perlu dilakukan perancangan dalam penataan lampu penerangan jalan agar dapat memenuhi standar 
penerangan jalan yang berlaku dan sesuai dengan kondisi jalan di Dusun Gitaq Demung. Dengan kondisi jalan di Dusun Gitaq Demung dengan lebar jalan 6 meter, maka dilakukan perancangan menggunakan jenis tiang lampu lengan tunggal dengan tinggi 10 meter, panjang lengan lampu 2 meter dan jarak dari tiang ke perkerasan jalan aspal adalah 1 meter. Untuk mendapatkan hasil iluminasi rata-rata yang sesuai dengan standar yang berlaku yaitu 6 - 12 lux, maka dipilih lampu sodium bertekanan tinggi (SON-T 150 Watt) dengan model susunan lampu satu sisi jalan (single side) dan jarak antar tiang lampu adalah 36 meter sehingga iluminasi rata-rata yang dihasilkan lampu pada permukaan jalan adalah 6,66 lux.

3. Jumlah titik lampu yang dibutuhkan pada lampu penerangan jalan di Dusun Gitaq Demung dengan total panjang jalan 250 meter berdasarkan perancangan adalah 7 (tujuh) titik lampu. Sehingga pemakaian energi listrik yang dibutuhkan pada penerangan jalan di Dusun Gitaq Demung adalah sebesar $378 \mathrm{kWh} /$ bulan dan tarif daya listrik yang harus dibayar untuk biaya lampu penerangan Jalan adalah sebesar Rp 349.083,-/bulan.

4. Pelaksanaan pengabdian kepada masayarakat di Dusun Gitaq Demung, Desa Genggelang, Kecamatan Gangga, Kabupaten Lombok Utara, oleh tim yang beranggotakan staf pengajar Jurusan Teknik Elektro Fakultas Teknik Universitas Mataram telah berjalan dengan lancar.

5. Tim pelaksana PPM dari Jurusan Teknik Elektro Unram yang beranggotakan 5 (lima) orang telah memberikan penyuluhan, pelatihan dan pembimbingan mengenai prinsip-prinsip dasar kelistrikan dalam kaitan lampu penerangan jalan umum (PJU), termasuk di dalamnya tentang tantangan dan kendala seperti teknologi PJU yang lebih efisien dan ekonomis, dalam hal ini memanfaatkan energi terbarukan.

6. Dengan pengenalan teknologi PJU dan tantangan, serta kendala pengembangan teknologi yang memanfaatkan energi terbarukan (surya, angin, mikrohidro), masyarakat dan aparat desa sangat antusias untuk mengupayakan pembangunan infrastruktur yang mendukung. Namun, karena berbagai keterbatasan, proses tersebut akan dilaksanakan secara bertahap.

\section{UCAPAN TERIMA KASIH}

Tim pelaksana PKM mengucapkan terima kasih kepada Universitas Mataram atas penyediaan fasiltas terkait administrasi pelaksanaan kegiatan Pengabdian Mandiri. Ucapan terima kasih juga diberikan bagi semua pihak-pihak yang terlibat dan telah membantu kegiatan ini kepada LPPM UNRAM, Pengelola Jurusan Teknik Elektro, dan Forum Mahasiswa Teknik Elektro Bali-Nusra yang telah memberi dukungan terhadap kegiatan pengabdian ini.

\section{DAFTAR PUSTAKA}

BSN (Badan Standarisasi Nasional). 2008. Spesifikasi Penerangan Jalan di Kawasan Perkotaan. Jakarta: Badan Standarisasi Nasional, 2008.

Direktorat Jendral Bina Marga Direktorat Pembinaan Jalan Kota. 1991. Spesifikasi Lampu Penerangan Jalan Perkotaan. Jakarta: Dirjen Bina Marga, Februari 1992.

Harsono, Budi. 1978. Perencanaan Sistem Penerangan Jalan. Bandung: Institut Teknologi Bandung. 